\title{
Terapia fotodinâmica: tratamento promissor na odontologia?
}

\author{
Photodynamic therapy: a promising treatment in dentistry? \\ KÉssia SuÊNIA FIDELIS de Mesquita \\ Doutoranda do Departamento de Clínica Infantil da Faculdade de \\ Odontologia de Ribeirão Preto - USP, Ribeirão Preto, SP. \\ Alexandra Mussolino de Queiroz \\ Professora Doutora do Departamento de Clínica Infantil da Faculdade de \\ Odontologia de Ribeirão Preto - USP, Ribeirão Preto, SP. \\ Paulo Nelson-Filho \\ Chefe do Departamento de Clínica Infantil da Faculdade de \\ Odontologia de Ribeirão Preto - USP, Ribeirão Preto, SP. \\ MARIA CRIstina Borsatto \\ Professora Titular do Departamento de Clínica Infantil da Faculdade de \\ Odontologia de Ribeirão Preto - USP, Ribeirão Preto, SP.
}

\section{RESUMO}

A terapia fotodinâmica (TFD) vem sendo pesquisada na odontologia a fim de estabelecer protocolos eficientes e indolores aos pacientes. É uma técnica sem efeitos colaterais, com custo acessível e que pode reduzir o tempo de reparação e a frequência de aparecimento de lesões. Os resultados podem ser observados poucas horas após a primeira irradiação com o laser. Três componentes são essenciais para a aplicação da técnica: a fonte de luz, o corante (fotossensibilizador) e o oxigênio. O objetivo dessa revisão de literatura é esclarecer o uso da terapia fotodinâmica na odontologia com alguns estudos realizados nos últimos anos.

Palavras-chave: TERAPIA FOTODINÂMICA, PROTOCOLOS INDOLORES, LUZ, FOTOSSENSIBILIZADOR, OXIGÊNIO.

\section{ABSTRACT}

Photodynamic therapy (PDT) has been researched in dentistry in order to provide effective and painless protocols to patients. This is a low cost technique, with no side effects, that can reduce repair time and the frequency of lesion appearance. Results can be observed a few hours after the first laser irradiation. Three components are essential for the technique's application: a light source, dye (photosensitizer) and oxygen. The purpose of this literature review is to clarify the use of photodynamic therapy in dentistry based on studies developed in recent years.

Keywords: PHOTODYNAMIC THERAPY, PAINLESS PROTOCOLS, LIGHT, PHOTOSENSITIZER, OXIGEN. 


\section{INTRODUÇÃO}

A terapia fotodinâmica (TFD), também conhecida como fotorradiação, fototerapia ou terapia fotoquímica, consiste do uso de um corante fotoativo (fotossensibilizador) ativado pela exposição à luz, com comprimento de onda específico, na presença de oxigênio. A transferência de energia do fotossensibilizador ativado resulta na formação de espécies de oxigênio tóxico, como o oxigênio singleto e radicais livres, capazes de danificar lipídios, ácidos nucleicos e outros componentes celulares. $^{1}$

Essa terapia surgiu como uma nova abordagem para substituir o uso de agentes antimicrobianos, os quais permitem 0 estabelecimento de patógenos oportunistas por meio do desenvolvimento da resistência dos micro-organismos, podendo alterar a microbiota da cavidade oral e o trato gastrointestinal. ${ }^{2}$ Dessa forma, o uso da TFD vem sendo difundido na odontologia, sobretudo no tratamento do câncer bucal, leucoplasia oral, líquen plano, câncer de cabeça e pescoço, infecções bacterianas e fúngicas. ${ }^{1}$

Apesar de a maioria das espécies bacterianas orais não absorver luz visível, a associação de alguns corantes pode sensibilizá-las, permitindo uma ação letal. ${ }^{3,4}$ $\mathrm{O}$ tratamento de doenças à base de luz vem sendo realizado há bastante tempo, porém a técnica da terapia fotodinâmica na odontologia começou a ser expandida com sistemática científica nos últimos tempos.

Assim, o objetivo desta revisão de literatura é relatar alguns estudos sobre as técnicas e as aplicabilidades clínicas e científicas da TFD, que traz perspectivas promissoras como tratamento em vários ramos da odontologia.

\section{REVISÃo dE LITERATURA}

\section{MECANISMO DE AÇÃO}

A terapia fotodinâmica foi inicialmente preconizada na odontologia para o tratamento de câncer. ${ }^{5}$ É uma técnica que utiliza substâncias com propriedades fotossensibilizadoras nos tecidos biológicos, ativadas pela presença de luz, com o objetivo de promover desinfecção nas regiões contaminadas. Células consideradas alvo da terapia fotodinâmica são coradas com o fotossensibilizador e irradiadas com luz, produzindo espécies reativas de oxigênio e radicais livres que resultam em morte celular. ${ }^{1,5-11}$

A TFD envolve vários parâmetros de dosimetria de luz, tais como: comprimento de onda, potência, tempo de exposição, taxa de fluência, fluência (dose), número de tratamentos e intervalos; por isso, não é fácil definir um protocolo clínico para essa técnica. Além disso, a fonte de luz e as características do fotossensibilizador devem ser consideradas. ${ }^{12}$ As características dos micro-organismos e do meio ambiente também influenciam nas consequências da irradiação com a luz laser na bactéria, em que o principal fator controlador da susceptibilidade da bactéria à luz laser é a sensibilidade à luz em um determinado comprimento de onda e seu estado fisiológico no momento da radiação. ${ }^{2}$

A molécula do fotossensibilizador absorve a luz irradiada com comprimento de onda específico e passa de um estado de baixa energia para um estado mais excitado (singleto), que pode voltar ao seu estado fundamental com emissão de fluorescência, ou sofrer transição para o estado tripleto (maior energia). O estado tripleto pode reagir com o oxigênio para a produção endógena de oxigênio singleto e outras espécies de radicais livres, causando uma rápida destruição seletiva do tecido alvo. ${ }^{1}$

Há dois mecanismos pelos quais o fotossensibilizador no estado tripleto pode reagir com biomoléculas. No tipo I ocorre transferência de hidrogênio diretamente do fotossensibilizador, produzindo íons ou elétrons/hidrogênio, removendo moléculas de substrato para formar os radicais livres. 
Estes radicais reagem rapidamente com o oxigênio, resultando na produção de espécies de oxigênio altamente reativas (superóxido, radicais hidroxila, peróxido de hidrogênio). As reações do tipo II produzem o estado eletronicamente excitado e altamente reativo de oxigênio (oxigênio singleto), ${ }^{1}$ que tem propriedades antimicrobianas e é capaz de reagir com proteínas da membrana celular, enzimas do citoplasma das bactérias e fungos, assim como destruir seu material genético. ${ }^{13}$ O dano causado dependerá tanto da tensão de oxigênio quanto da concentração do fotossensibilizador. ${ }^{1}$

O efeito antimicrobiano da terapia fotodinâmica não ocorre na ausência de luz, oxigênio e do fotossensibilizador. ${ }^{13} \mathrm{O}$ fotossensibilizador deve ser biologicamente estável, fotoquimicamente eficaz, possuir toxicidade mínima às células normais, seletividade pela célula-alvo, ser administrado de forma local, tópica, ou no interior da cavidade e, depois de um tempo ideal, ser irradiado com luz em dose e comprimento de onda adequados, utilizando-se fibra ótica, ponta difusora e outros, ou por iluminação direta da área exposta cirurgicamente..$^{6,7,10,14}$

O laser é, atualmente, a fonte de luz mais empregada para ativar os fotossensibilizadores em virtude da concentração elevada de energia (maior do que a luz natural), baixa divergência (geralmente paralela, ou seja, colimada), coerência (mesma fase) e monocromaticidade (mesma frequência). Dessa forma, é possível iluminar um meio composto por materiais diversos e só interagir com um determinado componente (seletividade) graças à propriedade da monocromaticidade, que seleciona o $\square$ da luz laser de tal forma que esta interage com uma determinada molécula dentro de um universo de várias. . $, 6,10$ Segundo Machado, ${ }^{6}$ a melhor fonte de radiação é a que possui baixo custo e maior quantidade de luz sem efeitos térmicos significativos.
Os lasers são conhecidos potencialmente como soft ou hard. Lasers soft têm potência de alguns $\mathrm{mW}$, enquanto os hard têm potência de, pelo menos, $1 \mathrm{~W}$. Também podem ser classificados como fotoquímicos (pela produção de radicais livres e outras espécies reativas), fototérmicos, fotoablativos (pelo rompimento das ligações químicas) ou fotomecânicos (pelo choque de ondas produzido pela dissipação do plasma). ${ }^{2}$

Lasers do tipo Nd:YAG vêm sendo bastante utilizados, embora apresentem elevado custo. É possível obter feixes de laser na faixa de 200 a $2000 \mathrm{~nm}$ utilizando as harmônicas de lasers $\mathrm{Nd}$ :YAG e alguns dispositivos ópticos. Existem lasers de diodo, de custo intermediário, que cobrem praticamente todo o espectro visível e infravermelho próximo. Estes fornecem luz pulsada de considerável potência com precisão sobre o tecido a ser irradiado. O LED, alternativa de baixo custo, também é um emissor de luz viável à TFD. ${ }^{1,6}$

\section{APLICABILIDADE NA ODONTOLOGIA}

A terapia fotodinâmica tem sua aplicabilidade destacada principalmente em pacientes idosos, ${ }^{7}$ especiais e pediátricos em virtude de seu caráter atraumático. ${ }^{10}$ Entre suas principais vantagens destacam-se: técnica não invasiva e conveniente para o paciente, baixo risco, possibilidade de repetição das doses, ${ }^{7}$ realização em ambulatório, seletividade, atuação local, melhoria na qualidade de vida, efeitos colaterais moderados, excelentes resultados estéticos com pouca ou nenhuma cicatriz, pouco investimento na infraestrutura, erradicação de micro-organismos em curto tempo, desenvolvendo pouca ou nenhuma resistência, evitando, inclusive, a perturbação da microbiota normal (útil como alternativa aos antibióticos e antissépticos). 1,12,15,16

A eficácia da TFD na eliminação de microorganismos patogênicos da cavidade oral promove a adequação do meio bucal com uma 
odontologia preventiva e conservadora. ${ }^{7-11}$ Erradicando-se as bactérias em lesões de cárie in vivo, a remoção mecânica de dentina infectada não seria necessária, tornando o tratamento mais fácil, tanto para o dentista quanto para o paciente, uma vez que as bactérias presentes na cavidade seriam mortas e a resistência do dente não seria comprometida pela remoção de tecido, como ocorre quando o dente é perfurado. . $^{15,17}$

A TFD tem tido resultados satisfatórios nas infecções orais, como no tratamento da candidíase; na periodontia, em procedimentos de raspagem e alisamento radicular, principalmente nas periodontites agressivas e nas perimplantites; na endodontia, como tratamento coadjuvante, por exemplo, em periodontites apicais refratárias e, atualmente, vem se destacando em dentística na redução de micro-organismos cariogênicos, como método de controle e tratamento da cárie dentária pela radiação de lasers de alta potência. 1,5,8,10,13,15

A TFD também é considerada um método efetivo para inativação de Candida albicans em próteses totais, utilizando-se porfirina (Photogem ${ }^{\circledR}$ ), 50 mg.L ${ }^{-1}$ por 10 minutos e aparelho de LED azul durante 26 minutos (37,5 J.cm-2). ${ }^{18}$ Os efeitos da TFD foram avaliados em ratos com candidose bucal, distribuídos em grupos que utilizaram laser e azul de metileno (fotossensibilizador), laser e fotossensibilizador isolados e sem nenhum dos tratamentos. A análise microscópica do dorso da língua demonstrou que o grupo da associação da TFD apresentou menos alterações epiteliais e menor resposta crônica inflamatória. O grupo que utilizou apenas laser apresentou alterações epiteliais mais intensas e respostas inflamatórias crônicas do que os demais grupos. ${ }^{19}$ Recentemente, Martins et al. ${ }^{20}$ também avaliaram os efeitos da terapia fotodinâmica sobre a patogenicidade da Candida albicans no dorso da língua de ratos com diferentes tratamentos: associação de laser e azul de metileno; laser e fotossensibilizador isolados e apenas solução fisiológica; o que permitiu concluir que a TFD reduziu as lesões microscópicas de candidíase experimental em ratos e inibiu a atividade de proteinase em $C$. albicans.

\section{Periodontia}

$\mathrm{Na}$ periodontia, alguns autores afirmam que a TFD pode tornar-se um método adjuvante no tratamento convencional da periodontite agressiva. Dessa forma, alguns estudos foram realizados na Faculdade de Odontologia de Ribeirão Preto da Universidade de São Paulo (Forp/USP), onde compararam a raspagem e alisamento radicular, utilizando-se instrumentos manuais e terapia fotodinâmica, por meio de uma fonte de laser com um comprimento de onda de $690 \mathrm{~nm}$ associada ao fotossensibilizador fenotiazina no tratamento de periodontite agressiva. As duas técnicas tiveram resultados clínicos semelhantes no tratamento não cirúrgico da periodontite agressiva. ${ }^{21} \mathrm{O}$ fluido crevicular foi coletado após tratamento com TFD ou da raspagem e alisamento radicular, no intuito de observar os níveis de citocinas no fluido gengival. Detectaram que ambos os métodos levaram a reduções estatisticamente significativas no nível de TNF- $\alpha$ após 30 dias, ${ }^{22}$ sugerindo, mais uma vez, a eficácia da TFD. Em um estudo recente, foi avaliado o efeito de uma única aplicação da TFD sobre o perfil microbiológico e padrão de citocinas em cães. A doença periodontal foi induzida e os cães foram tratados com TFD e raspagem e alisamento radicular isolados e associados. Os níveis da maioria das espécies bacterianas foram reduzidos em uma semana pós-terapia para todos os tratamentos, entretanto, um aumento de Prevotella intermedia, Prevotella nigrescens e Tannerella forsythia foi observado para TFD e sua associação com raspagem e alisamento radicular. Após quatro semanas, 
foi notada a presença de Porphyromonas gingivalis e Treponema denticola em todos os tratamentos. No entanto, uma redução notável de Aggregatibacter actinomycetemcomitans foi observada na TFD. Os resultados foram similares em todos os tratamentos, sugerindo que a raspagem e alisamento radicular, a TFD em uma única aplicação e a associação entre elas afetam diferentes espécies de bactérias e têm efeitos semelhantes na expressão de citocinas durante o tratamento da periodontite. ${ }^{23}$

O efeito da terapia fotodinâmica como adjuvante à raspagem e alisamento radicular também foi avaliado, clínica e microbiologicamente, pela reação em cadeia da linha de base da polimerase (PCR) em pacientes com periodontite crônica localizada, infectados por F. nucleatum. Nesse experimento, os sintomas e as manifestações da inflamação periodontal, assim como a profundidade das bolsas periodontais, foram reduzidos. ${ }^{24}$

\section{ENDODONTIA}

Já na endodontia, a eficácia da TFD foi testada comparando-a à irrigação isolada com hipoclorito de sódio ( $\mathrm{NaOCl}$ ) a 3\% no tratamento de 35 canais radiculares. Os autores utilizaram combinações variadas do fotossensibilizador, concentração e dose de luz. Esse estudo mostrou que o uso combinado de um agente fotossensibilizante e um laser de baixa potência direcionado à cavidade de acesso teve efeito bactericida para $S$. intermedius em canais radiculares, mas não eliminou totalmente as bactérias, ao contrário de $\mathrm{NaOCl}$ a $3 \% .{ }^{25}$ Trinta tubos de ensaio contendo caldo $\mathrm{BHI}$ (brain heart infusion - Difco, EUA) inoculados com cepa padrão de Enterococcus faecalis foram avaliados, comparando-se à ação isolada do hipoclorito de sódio a 1\%, do laser AsGaAl, do corante azuleno 25\%/Endo-PTC e a TFD. O hipoclorito de sódio a $1 \%$ mostrou-se eficaz na eliminação dos micro-organismos, a TFD apenas reduziu o número de bactérias e o laser e o corante não exerceram nenhuma atividade inibidora do crescimento bacteriano isoladamente. ${ }^{26}$

O efeito antimicrobiano da TFD foi testado em associação com o tratamento endodôntico convencional. As amostras microbiológicas foram realizadas após acessar o canal radicular, a realização da endodontia e a TFD. Ao final da primeira sessão, o canal radicular foi preenchido com hidróxido de cálcio e, depois de uma semana, a TFD foi realizada. Os resultados sugeriram que a TFD adicionada ao tratamento endodôntico reforça a diminuição da carga bacteriana. ${ }^{27}$ O mesmo resultado foi encontrado ao utilizar essa associação depois de desenvolvida resistência antimicrobiana por uso de antibióticos. Nesse estudo, todos os pacientes tiveram pelo menos um micro-organismo resistente ao antibiótico. A terapia endodôntica isolada produziu uma redução significativa no número de espécies microbianas enquanto a combinação do tratamento endodôntico com a TFD eliminou todas as espécies, podendo ser uma abordagem adequada para o tratamento de infecções orais. ${ }^{28}$

\section{DENTISTICA}

Pesquisas realizadas na Faculdade de Odontologia da USP e na Universidade de Aachen, na Alemanha, demonstraram que a TFD causa modificações químicas e estruturais no esmalte dentário e torna-o mais resistente às lesões provocadas pela cárie. ${ }^{8}$ Com o intuito de avaliar o efeito antimicrobiano do azul de toluidina O (TBO), em combinação com o laser hélio/neônio ( $\mathrm{HeNe}$ ), ou um diodo emissor de luz (LED) com densidades de energia entre 49 e $294 \mathrm{~J} / \mathrm{cm}^{2}$ sobre a viabilidade e arquitetura de biofilme de Streptococcus mutans, alguns autores cultivaram biofilme sobre discos de hidroxiapatita e saliva artificial suplementada 
com $2 \%$ de sacarose, quatro vezes ao dia, sendo foi possível observar redução significativa na viabilidade de S. mutans. ${ }^{29}$

\section{ESTOMATOLOGIA}

O laser de baixa potência tem sido utilizado no tratamento do herpes labial para diminuir a frequência de aparecimento das lesões, proporcionando satisfação e conforto aos pacientes. Nesse sentido, a TFD foi realizada in vivo para o tratamento de herpes labial na fase de vesícula, aplicando-se o corante azul de metileno a 0,01\% (Chimiolux ${ }^{\circledR}$ - Hyrofarma) e laser de baixa potência de AsGaAl. Inicialmente, foi utilizado o laser com comprimento de onda de $660 \mathrm{~nm}$, densidade de energia de 2,8 J, $100 \mathrm{~mW}$ de potência, 2,7 $\mathrm{J}$ de energia e $28 \mathrm{~s}$, em quatro pontos, modo contínuo e área do feixe de $0,028 \mathrm{~cm}^{2}$. Seis horas após, a luz foi irradiada com o mesmo aparelho de laser, com comprimento de onda de $685 \mathrm{~nm}$, densidade de energia de $20 \mathrm{~J} / \mathrm{cm}^{2}$, $40 \mathrm{~mW}$ de potência, $0,54 \mathrm{~J}$ de energia, $14 \mathrm{~s}$ por ponto e modo contínuo. Esse último protocolo foi repetido 24 horas e sete dias após. Houve aceleração na reparação da lesão em apenas uma semana e a paciente não sentiu dor nem desconforto, porém, seis horas após a TFD, já foi detectada a melhoria dos sinais e sintomas do herpes labial. ${ }^{15}$ Ao utilizarem o azul de metileno a $0,01 \%$ e laser de baixa potência (comprimento de onda de $660 \mathrm{~nm}$, densidade de energia de $120 \mathrm{~J} / \mathrm{cm}^{2}$, potência de $40 \mathrm{~mW}$ e 4,8J de energia) por 2 minutos em quatro pontos da lesão, e, repetindo-se em 24 e 72 horas e uma semana após, com densidade de energia $3,8 \mathrm{~J} / \mathrm{cm}^{2}$, potência de $15 \mathrm{~mW}$ e 0,6 J de energia, respectivamente, a TFD também foi eficaz e não apresentou efeitos colaterais nos parâmetros utilizados. ${ }^{12}$

\section{Conclusão}

Com base na revisão de literatura exposta e nos últimos estudos sobre terapia fotodinâmica, torna-se evidente que ainda não existem técnicas padronizadas para seu uso em consultório odontológico. São necessários mais estudos e relatórios de acompanhamento clínico para que a abordagem seja útil no tratamento das diversas situações.

\section{REFERÊNCIAS}

1. Konopka K, Goslinski T. Photodynamic therapy in dentistry. J Dent Res. 2007 Aug; 86(8): 694-707.

2. Wilson M. Bactericidal effect of laser light and its potential use in the treatment of plaque-related diseases. Int Dent J. 1994 Apr; 44: 182-9.

3. Dobson J, Wilson M. Sensitization of oral bacteria in biofilms to killing by light from a lowpower laser. Archs oral Biol. 1992 Nov; 37(11): 883-7.

4. Wilson M, Dobson J, Sarkar S. Sensitization of periodontopathogenic bacteria to killing by light from a low-power laser. Oral Microbiol Immunol 1993 Jun; 8: 182-7.

5. Zanin ICJ, Brugnera-Junior A, Zanin F, Gonçalves RB. Terapia fotodinâmica na odontologia (T.F.D.). RGO 2003; 51(3): 179-82.

6. Machado AEH. Terapia fotodinâmica: princípios, potencial de aplicação e perspectivas. Quím Nova. 2000; 237-43.

7. Perussi JR. Inativação fotodinâmica de microrganismos. Quím Nova. 2007; 30: 988-94.

8. Oliveira B. Laser: a LUZ para diversos tratamentos e procedimentos odontológicos. APCD Jornal. 2008.

9. Pinheiro ALB. Novos caminhos para o exercício da odontologia. Rev Assoc Paul Cir Dent. 2008; 62(5): 342-51.

10. Baptista A. Efeito da terapia fotodinâmica na doença cárie. Estudo in vivo [Dissertação]. São Paulo: Instituto de pesquisas energéticas e nucleares - Faculdade de odontologia da Universidade de São Paulo. 2009.

11. Gonçalves PVAJ, Rocha WMS, Mota JMLF, Cortes ME, Poletto LTA. Efeito antimicrobiano 
da terapia fotodinâmica em lesões cariosas - estudo in vivo [resumo expandido]. XVIII Encontro do GBPD. Jan/2009. Foz do Iguaçu - PR. Brasil.

12. Marotti J, Aranha ACC, Eduardo CP, Ribeiro MS. Photodynamic therapy can be effective as a treatment for Herpes simplex labialis. Photomed Laser Surg. 2009 Apr; 27(2): 357-63.

13. Sousa GR, Prates RA, Silveira LB, Amorim JCF, Ferreira MVL, Pinotti M. Efeito antimicrobiano da terapia fotodinâmica em lesões cariosas - estudo in vivo [nota publicada em: http:// pt-br.mmo.com.br/, 2010]. MM Optics Ltda. ampliando conhecimentos. Tecnotes. Jan/2007. Ano 3. Número 11.

14. Ackroyd R, Kelty C, Brown N, Reed M. The History of Photodetection and Photodynamic Therapy. Photochem Photobiol. 2001 Nov; 74(5): 656-69.

15. Wilson M. Lethal photosensitization of oral bacteria and its potential application in the photodynamic therapy of oral infections. Photochem Photobiol Sci. 2004 May; 3(5): 4128.

16. Marotti J, Aranha ACC, Eduardo CP, Ribeiro MS. Tratamento do herpes labial pela terapia fotodinâmica. Rev Assoc Paul Cir Dent. 2008; 62(5): 370-3.

17. Burns T, Wilson M, Pearson GJ. Killing of cariogenic bacteria by light from a gallium aluminium arsenide diode laser. J Dent. 1994 Oct; 22: 273-8.

18. Sakima SA, Mima EGO, Bagnato VS, Pavarina AC. Efetividade da terapia fotodinâmica na inativação de Candida albicans presentes em próteses totais [resumo]. 61 ${ }^{\mathrm{a}}$ Jornada Odontológica e 21 ${ }^{\text {a }}$ Jornada Acadêmica. Revista de Odontologia da Unesp. Ago/2007; 36: número especial. Araraquara - SP. Brasil.

19. Junqueira JC, Martins JS, Faria RL, Colombo CED, Jorge AOC. Photodynamic therapy for the treatment of buccal candidiasis in rats. Lasers Med Sci 2009 Nov; 24: 877-84.

20. Martins JS, Junqueira JC, Faria RL, Santiago NF, Rossoni RD, Colombo CED et al. Antimicrobial photodynamic therapy in rat experimental candidiasis: evaluation of pathogenicity factors of Candida albicans. OOOOE 2011 Jan; 111: 101-7.

21. De Oliveira RR, Schwartz-Filho HO, Novaes AB, Taba M. Antimicrobial photodynamic therapy in the non-Surgical treatment of aggressive periodontitis: a preliminary randomized controlled clinical study. J Periodontol. 2007 Jun; 78(6): 965-73.

22. De Oliveira RR, Schwartz-Filho HO, Novaes AB, Garlet GP, de Souza RF, Taba M, et al. Antimicrobial photodynamic therapy in the nonsurgical treatment of aggressive periodontitis: cytokine profile in gingival crevicular fluid, preliminary results. J Periodontol. 2009 Jan; 80(1): 98-105.

23. De Oliveira RR, Novaes AB Jr, Garlet GP, de Souza RF, Taba M, Sato S, et al. The effect of a single episode of antimicrobial photodynamic therapy in the treatment of experimental periodontitis. Microbiological profile and cytokine pattern in the dog mandible. Lasers Med Sci. 2011 May; 26(3): 359-67.

24. Sigusch BW, Engelbrecht $M$, Völpel A, Holletschke A, Pfister W, Schütze J. Full-mouth antimicrobial photodynamic therapy (PDT) in F. nucleatum infected periodontitis patients. J Periodontol. 2010 Jul; 81(7): 975-81.

25. Seal GJ, Ng Y-L, Spratt D, Bhatti M, Gulabivala $\mathrm{K}$. An in vitro comparison of the bactericidal efficacy of lethal photosensitization or sodium hyphoclorite irrigation on Streptococcus intermedius biofilms in root canals. Int Endod J. 2002 Mar; 35(3): 268-74.

26. Castro MR, Brasil CO, Arisawa EAL. Avaliação in vitro do efeito da terapia fotodinâmica em suspensão de enterococcus faecalis. XEncontro Latino Americano de Iniciação Científica. VI Encontro Latino Americano de Pós-Graduação da Universidade do Vale da Paraíba. 2006. São José dos Campos - SP. Brasil

27. Garcez AS, Nuñez SC, Hamblim MR, Ribeiro MS. Antimicrobial effects of phtotodynamic therapy on patients with necrotic pulps and periapical lesions. J Endod. 2010 Sep; 36(9): 1463-6.

28. Garcez AS, Nuñez SC, Hamblim MR, Suzuki H, Ribeiro MS. Photodynamic therapy associated with conventional endodontic treatment in 
patients with antibiotic-resistant microflora: A preliminary report. J Endod. 2010 Sep; 36(9): 1463-6.

29. Zanin ICJ, Gonçalves RB, Brugnera-Junior A, Hope CK, Pratten J. Susceptibility of Streptococcus mutans biofilms to photodynamic therapy: an in vitro study. J Antimicrob Chemother. 2005 Aug; 56(2): 324-30.

Submetido em: 9-7-2013

Aceito em: 10-9-2013 